\title{
Stress-induced ulceration in adrenalectomized and normal rats
}

\author{
C. WAYNE SIMPSON, LINDA G. M. WILSON, LEO V. DiCARA, K. JOHN JARRETT, \\ and \\ BERNARD J. CARROLL \\ Mental Health Research Institute, University of Michigan Medical Center, Ann Arbor, Michigan 48104
}

\begin{abstract}
This experiment examined the influence of plasma corticosterone on stress-induced ulceration in restrained rats. Gastric pathology and plasma corticosterone levels were examined in normal (UNOP) and adrenalectomized (ADX) rats under two conditions of shock predictability. The severity of the gastric ulceration in unoperated rats given noncontingent presentations of a tone and an electric shock was greater than in subjects receiving shocks contingent upon CS presentation. When ulcer pathology was evaluated for ADX animals, no differences were found between the predictable and the unpredictable shork groups. The results were discussed in terms of the necessary and sufficient conditions for stomach ulcer formation as a function of shock predictability and restraint stress and the necessity to investigate alternative hypotheses.
\end{abstract}

Recent evidence has suggested that several physiological mechanisms contribute to gastric ulcer formation in restrained rats. Weiss $(1968 ; 1970)$ has examined the influence of several psychological factors on the production of gastric ulcers. He has shown that the severity of ulceration was attenuated in rats for which shock onset was reliably predicted by an external stimulus (CS) compared with rats for which shock onset was not contingent upon CS presentation. In addition, Weiss (1970) reported that the levels of plasma corticosterone paralleled the development of ulcers in the three groups tested: Blood samples from rats receiving unpredictable shocks contained high titers of the steroid, while samples from rats in the predictable and the no-shock control groups had significantly lower levels. If the formation of ulcers can be attributed to plasma corticosterone levels, then the absence of group differences in steroid level should preclude differences in the severity of stress-induced ulcers. Specifically, the present experiment tested the hypothesis that poststress differences in plasma corticosterone levels accounted for the variation in gastric pathology among the unpredictable, predictable, and nonshocked groups.

\section{METHOD}

\section{Subjects}

Thirty adult male Sprague-Dawley rats weighing 300-350 g were purchased from Spartan Research Animals, Haslett,

This research was supported by Grant MH 21403 from the National Institutes of Mental Health and Grant AHA 73774 from the American Heart Association to L. V. DiCara. The authors gratefully acknowledge the technical assistance of Mr. William Allen and $\mathrm{Mr}$. Ronald Derman. Address reprint requests to: Dr. C. Wayne Simpson. Department of Psychological Sciences, Purdue University, West Lafayette, Indiana.
Michigan. All animals were given free access to food and water for 1 week prior to their use in the study. Rats were individually housed in wire mesh cages in a room maintained on a 12-h-light/12-h-dark cycle.

\section{Apparatus}

Three cylinders, measuring $20.3 \times 5.7 \mathrm{~cm}$, were used to restrain the subjects during the stress session. Restrainers were constructed of 23-ga. galvanized hardware cloth, with a stationary wooden panel at one end to prevent the rat from leaving the restrainer. An adjustable panel at the other end permitted the rat to enter the tube and allowed the experimenter to adjust the length of the tube to the size of the individual rat. Each restrainer was suspended in a Plexiglas cradle and placed into individual BRS/Foringer acoustic chambers, each measuring $73.7 \times 47.0 \times 41.9 \mathrm{~cm}$. Each chamber was equipped with an exhaust fan which provided a continuous background masking noise. The chambers were not illuminated during the experiment.

The conditioned stimulus (CS) was provided by a $3.1-\mathrm{kHz}$ Sonalert at $85 \mathrm{~dB}$ SPL. The Sonalert was placed approximately $12.0 \mathrm{~cm}$ in front of the subject's head in the chamber. Unconditioned stimuli (US) were $3.5 \mathrm{~mA}$ RMS half-wave rectified $60-\mathrm{Hz}$ shocks delivered to the subject's tail via pairs of 18.0-ga. stainless steel hypodermic needles wired in series for two chambers to the unscrambled output of a Lehigh Valley scrambler/shocker. The output was of the series resistance regulation type, where the output resistance was $100 \mathrm{kohm}$. The shock source was disconnected from the third chamber. The CS and US presentations to the two experimental chambers were programmed with BRS/LVE solid state logic modules.

\section{Procedure}

Following their arrival in the lab, the rats were randomly assigned to one of two groups: (1) An adrenalectomized group (ADX): Subjects were anesthetized with chloral hydrate and pentobarbital (Equithesin), $3 \mathrm{cc} / \mathrm{kg}$ body weight, prior to the excision of one adrenal gland. Following surgery, subjects were allowed a 1-week recovery period before reanesthetization and the removal of the remaining adrenal. Two weeks recovery on ad-lib food and water, plus continuous access to a $.9 \%$ saline solution, followed the second stage of surgery. (2) An unoperated group (UNOP): Subjects did not experience any surgical manipulation prior to the start of the experiment. After 
Table 1

Mean Data ( \pm SEM) for Gastric Lesions and Corticosterone Levels in Adrenalectomized and Unoperated Rats

\begin{tabular}{lllcccc}
\hline $\begin{array}{c}\text { Treat- } \\
\text { ment }\end{array}$ & Group & $\mathrm{N}$ & $\begin{array}{c}\text { Mean Number } \\
\text { of Lesions }\end{array}$ & $\begin{array}{c}\text { Mean Total } \\
\text { Length of } \\
\text { Lesion }(\mathrm{mm})\end{array}$ & $\begin{array}{c}\text { Mean of Median } \\
\text { Length of } \\
\text { Lesion }(\mathrm{mm})\end{array}$ & $\begin{array}{c}\text { Plasma } \\
\text { Corticosterone } \\
(\mathrm{mg} / 100 \mathrm{ml})\end{array}$ \\
\hline & UPS & 5 & $4.8 \pm 0.7$ & $9.0 \pm 1.5$ & $1.7 \pm 0.1$ & $11.5 \pm 3.8$ \\
& PS & 5 & $2.4 \pm 0.4$ & $1.9 \pm 0.4$ & $.7 \pm 0.1$ & $9.6 \pm 0.7$ \\
UNOP & NS & 5 & $6.8 \pm 3.1$ & $16.8 \pm 11.9$ & $1.6 \pm 0.5$ & $8.9 \pm 2.7$ \\
& UPS-PS & & $\mathrm{p}<.025$ & $\mathrm{p}<.005$ & $\mathrm{p}<.0005$ & $\mathrm{p}>.05$ \\
& PS-NS & & $\mathrm{p}>.05$ & $\mathrm{p}>.05$ & $\mathrm{p}>.05$ & $\mathrm{p}>.05$ \\
& UPS-NS & & $\mathrm{p}>.05$ & $\mathrm{p}>.05$ & $\mathrm{p}>.05$ & $\mathrm{p}>.05$ \\
& UPS & 3 & $9.7 \pm 5.2$ & $7.3 \pm 3.8$ & $0.8 \pm 0.2$ & $2.0 \pm 0.0$ \\
& PS & 3 & $5.3 \pm 4.4$ & $6.0 \pm 5.6$ & $0.5 \pm 0.3$ & $2.7 \pm 0.7$ \\
ADX & NS & 3 & $8.7 \pm 3.8$ & $9.9 \pm 4.2$ & $1.3 \pm 0.3$ & $2.2 \pm 0.2$ \\
& UPS-PS & & $\mathrm{p}>.05$ & $\mathrm{p}>.05$ & $\mathrm{p}>.05$ & $\mathrm{p}>.05$ \\
& PS-NS & & $\mathrm{p}>.05$ & $\mathrm{p}>.05$ & $\mathrm{p}>.05$ & $\mathrm{p}>.05$ \\
& UPS-NS & & $\mathrm{p}>.05$ & $\mathrm{p}>.05$ & $\mathrm{p}>.05$ & $\mathrm{p}>.05$ \\
\hline
\end{tabular}

the recovery period, the ADX and UNOP rats were separated into five groups of three rats each and were matched within the triplet for body weight $( \pm 10 \mathrm{~g})$. Following 24 -h food deprivation, triplets were weighed and placed into individual wire mesh restrainers. Each subject's tail was cleaned, and electrode paste was applied to a small area on either side of the tail. The shock electrodes were fastened on top of the paste. Adhesive tape was placed across the electrodes to prevent excessive dessication of the paste. Tail resistance was measured independently for each rat, and the electrodes were adjusted until the resistances were separated by no more than $10 \mathrm{kohm}$. After a 30-min adaptation period, rats in the triplet were randomly assigned to one of three shock conditions. Rats in the predictable shock (PS) group were presented with a tone $10 \mathrm{sec}$ before the onset of a $3.5-\mathrm{mA} 2$-sec tail shock. Paired CS-US presentations occurred on a VI $60-\mathrm{sec}$ schedule over 19 consecutive hours. Subjects in the unpredictable shock (UPS) groups received the same number of $\mathrm{CS}$ and US presentations as did the PS groups. However, the presentation of the CS bore no systematic relationship to US onset. Nonshocked (NS) rats were maintained in their restrainers for $19 \mathrm{~h}$ but received neither CS nor US exposures.

Following the 19-h stress situation, all rats were removed from their restrainers, weighed, and returned to their home cages. They remained in their cages for $6 \mathrm{~h}$ without food. Subjects were then sacrificed with an overdose of Equithesin and decapitated. Blood was immediately collected in heparinized Vacutainer test tubes and assayed for plasma corticosterone by a modification of Murphy's (1967) method. Stomachs were removed, cut along the lesser curvature, rinsed in distilled water, and pinned to a paraffin specimen dish with the glandular portion fully exposed Ulcers in the glandular portion of the stomach were identified according to the description of several investigators (Ader, 1963; Tran \& Greg, 1974) and were counted under a Zeiss dissecting microscope at a constant manification of $16 \mathrm{X}$.

\section{RESULTS}

Table 1 summarizes the data on the major measures of gastric ulceration and plasma corticosterone level $(\mathrm{mg} / 100 \mathrm{ml})$ as a function of shock condition for both UNOP and ADX subjects. Correlated $t$ tests on differences between matched subjects were performed on these measures for the ADX and UNOP groups separately. The $t$ test for matched subjects has been used previously by Weiss (1971) to evaluate differences in ulcer pathology in matched triplets of rats.
The total number of gastric lesions (both measurable and pinhole) did not differ among the three shock conditions for the UNOP animals. However, Table 1 demonstrates that the stomachs of UPS rats contained a greater mean number of measurable lesions (e.g., longer than $.25 \mathrm{~mm}$ ) than did those from the matched PS group $(p<.025)$. The NS animals did not differ from either the UPS or the PS subjects on this measure $(p>.05$, or both). Similarly, the mean total lesion length, as well as the mean of the median ulcer length, was significantly longer in rats experiencing unpaired tone-shock presentations than in PS groups $(p<.005 ; p<.0005$, respectively). The NS subjects did not differ between either PS or UPS groups.

The more severe gastric pathology evident in the unoperated UPS rats supports Weiss's (1968) earlier data. Plasma corticosterone levels for UPS rats were higher $6 \mathrm{~h}$ poststress than those for either PS or NS rats. However, contrary to Weiss's (1970) earlier reports, these differences were not statistically significant (cf. Weiss, 1971).

Analyses for the ADX rats demonstrated no significant differentiation among the UPS, PS, and NS subjects on the total number of measurable lesions, the total length of lesions, or the median length of the ulcers during the poststress period. Plasma corticosterone assays demonstrated that, in all instances, the adrenal glands had been completely removed during surgery. Only trace amounts of corticosterone were found in poststress blood samples. Additionally, no differences were found in levels of the steroid among the UPS, PS, and NS groups.

Pearson product-moment correlation coefficients were computed separately for ADX and UNOP rats between corticosterone levels and each of the other dependent measures of ulceration. Despite the fact that corticosterone correlated +.42 with the total number of lesions for UNOP rats, no statistically significant correlations were uncovered for either the ADX or the UNOP groups. 
Finally, the ADX and UNOP groups were compared directly on the measures of gastric ulceration noted, by means of the $t$ test for independent groups. No significant differences between the ADX and UNOP groups were demonstrated for any of the measures of ulceration previously described. The UNOP group, however, had a significantly $(\mathrm{p}<.001)$ higher level of plasma corticosterone than the ADX group.

\section{DISCUSSION}

Much evidence indicates that psychological factors can affect both pituitary-adrenal cortical and sympathetic-adrenal medullary activity and that all three factors can be related to the etiology of gastric ulcers. The present study suggests a complex interaction among adrenalectomy, shock unpredictability, and restraint stress. The data support Bonfils, Liefooghe, Rossi, and Lambling's (1957) reports that adrenalectomy does not affect the incidence of restraint-induced ulceration in rats (cf. Brodie \& Hanson, 1960: Hanson, 1963). However, removal of the adrenals, with its concomitant elimination of both cortical and medullary hormones, eradicated the differentiation in severity of ulceration based on shock predictability. Weiss (1970) found higher plasma corticosterone levels in unpredictable shock groups both 5 and $24 \mathrm{~h}$ after the stress onset, compared with subjects in predictable shock groups. In the present study, unoperated UPS rats had higher mean levels of corticosterone $6 \mathrm{~h}$ following the end of a 19-h stress period than did PS rats. However, the additional 1-h poststress delay in this study, compared to Weiss's procedure, may explain the inability to obtain a statistically significant difference. The correlation between corticosterone levels and the total number of lesions was +.42 for the unoperated stressed groups. Although this relationship indicated that as corticosterone increased ulceration became more severe, it was not significant.

The effect of the elimination of cortical hormones in the present study appears confounded with the removal of adrenal medullary influences, primarily epinephrine, on ulcer formation. Phillips and Boone (1968) found that bilateral adrenal sympathectomy, which depressed blood levels of epinephrine but left cortical activity intact, eliminated ulcers in rats subjected to an extended period of physical restraint. Furthermore, the authors confirmed that adrenalin supplements in similar surgical preparations led to the development of gastric lesions in their immobilized animals. However, when adrenal epinephrine had been eliminated by bilateral adrenalectomy in the present experiment, the degree of ulceration was unchanged compared with intact unoperated subjects in the same shock-restraint procedure.

Mason (1968) has noted that environmental unpredictability, in combination with noxious stimulation and coping behavior, often leads to elevations in both epinephrine and plasma corticosterone. In addition, changes in serotonin (Lambert, Descos, Pasquier, \& Martin, 1965), histamine (Hay, Varco, Code, \& Wangensteen, 1942), and norepinephrine (Weiss, Stone, \& Harrell, 1970), as well as changes in pepsinogen levels (Ader, 1963; Ader, Beels, \& Tatum, 1960), and gastric acidity (Hay et al., 1942) have been implicated in ulcer formation in rats. It appears that removal of any one factor does not completely protect the stomach from ulceration in certain stressful situations. However, the ability of physiological indicators of stress to vary with psychological input enables the subject to reduce somatic involvement.

\section{REFERENCES}

Ader, R. Plasma pepsinogen level as a predictor of susceptibility to gastric erosions in the rat. Psychosomatic Medicine. $1963,25,221-232$.

Ader, R., Beels, C. C., \& Tatum, R. Blood pepsinogen and gastric erosions in the rat. Psychonomic Medicine, 1960, 22, $1-13$

Bonfils, S., Liefooghe, G., Rossi, G., \& Lambling, A. L'ulcère de constrainte du rat blanc. Modifications de la fréquence lesionelle par différents procédés operatoires et pharmacodynamie. Sociéte' de Biologie, Paris, Compte Rendus Hébdomadaires des Séances et Memoires de les Société de Biologie, 1957, 151, 1149-1150.

Brodie, D. A., \& Hanson, H. M. A study of the factors involved in the production of gastric ulcers by the restraint technique. Gastroenterology, 1960, 38, 353-360.

Hanson, H. M. Restraint and gastric ulcers. Journal of Neuropsychiatry, 1963, 4, 390-395.

Hay, L. J., Varco, R. L., Code, D. F., \& Wangensteen, O. H. The experimental production of gastric and duodenal ulcers in laboratory animals by intramuscular injection of histamine in beeswax. Surgery, Gynecology, and Obstetrics, 1942, 75, 170-182.

Lamber, R., Descos, L., Pasquier, J., \& Martin, M. Ulceres médicamentaux chez le rat: V. La sérotonine. Gastroenterologia, 1965, 103, 365-381.

Mason, J. W. A review of psychoendocrine research on the sympathetic adrenal medullary system. Psychosomatic Medicine, 1968, 30, 6.31-653.

Murphy. B. E. P. Some studies of the protein-binding of steroids and their application to the routine micro and ultramicro measurement of various steroids in body fluids by competitive protein-binding radioassay. Journal of Clinical Endoc rinology, 1967, 27, 973-990.

Phillips, J. D., JR., \& Boone, D. D. Effects of adrenalin supplement on the production of stress induced ulcers in adrenal sympathectomized male rats. Proceedings of the 76th Annual Convention of the American Psychological Association, 1968, 3. 261-262.

TrAN, T. A., \& GREGG, R. V. Transmittal of restraintinduced gastric ulcers by paraboisis in rats. Gastroenterology, 1974, 66. 63-68.

Weiss, J. M. Effects of predictable and unpredictable shock on development of gastrointestinal lesions in rats. Proceedings of the 76th Annual Convention of the American Psychological Association, 1968, 3, 263-264.

WeISS, J. M. Somatic effects of predictable and unpredictable shock. Psychosomatic Medicine, 1970, 32, 397-408.

Weiss. J. M. Effects of coping behavior in different warning signal conditions on stress pathology in rats. Journal of Comparative and Physiological Psychology, 1971. 77, 1-13.

Weiss, J. M., Stone, E. A., \& Harrell, N. Coping behavior and brain norepinephrine level in rats. Journal of Comparative and Physiological Psychology, 1970, 72, 153-160.

(Received for publication June 2, 1975.) 